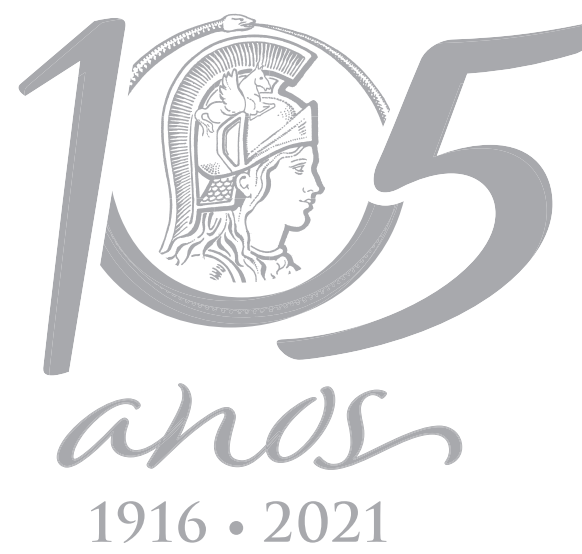

\title{
An Investigation of The Effect of Extracellular Vesicles Isolated from Mouse Embryonic Fibroblasts on Wound Healing in an Experimental Diabetic Mouse Model
}

\author{
AHMET S. BOZKURT, DAVUT S. KAPLAN, ALI O. ÇERIBAŞI, MUSTAFA ORKMEZ, \\ ASUMAN ÇANAK \& MEHMET TARAKÇIOĞLU
}

\begin{abstract}
This study aimed to investigate the effects of Extracellular Vesicles (EV) secreted from mouse embryonic fibroblasts EV on wound healing of full-thickness skin defect in a diabetic mouse model. The study included both in vitro and in vivo experimental studies 82 mice. In the in vitro stage of the experimental study, hysterectomy was performed on two mice between the 13-14th days of pregnancy and then EV was isolated by cell culturing. VEGF, IL-6, and TNF- $\alpha$ biomarkers were examined in tissue homogenate. Moreover, tissue taken from wound area was also subjected to histopathologic scoring. EV augmented the effect of VEGF. Therefore promoted angiogenesis increases the transport of cells, essential oxygen and nutrients in the wound area. Extracellular vesicles isolated from mouse embryonic fibroblasts have been found to accelerate wound healing in diabetes. The findings obtained from this experimental study indicate that EV isolated from mouse embryonic fibroblasts accelerate the wound healing process in experimentally induced-diabetes in mice.
\end{abstract}

Key words: mouse, embryonic, fibroblast, extracellular, vesicles.

\section{INTRODUCTION}

Fibroblasts are the primary cells of connective tissues, which are relatively undifferentiated mesodermal cell types abundantly found in the connective tissue and they play a role in various processes of wound healing (Rodero \& Khosrotehrani 2010). Mouse embryonic fibroblast cells (MEFs) have a similar structure to stem cells, which are frequently used as feeder cells because they harbor various growth factors to promote the self-renewal of embryonic stem cells as well as their undifferentiated growth (Qin et al. 2018). One of the critical factors released from EV isolated from MEFs is the Fibroblast Growth Factor (FGF). FGFs are structurally related mitogens that regulate the differentiation of various cells. In addition to promoting growth, FGFs are thought to play various roles in controlling cellular differentiation in a wide variety of cell types. FGFs have a polypeptide structure. Early embryonic developments have an essential role in tissue repair and development of metabolic and physiological homeostasis by FGF. 22 members of the FGF family have been identified in mice (Haub \& Goldfarb 1991). Wound healing is an extremely complicated process that involves a series of complex dynamic events in several stages (Hormozi et al. 2017). Wound healing is a complex process that consists of integrated stages such as inflammation, granulation tissue formation, re-epithelialization, matrix formation, and remodeling (Barrientos et al. 2008). 
In light of this information, this study aimed to investigate the role of $\mathrm{EV}$ isolated from MEF in wound healing in an experimental diabetic mouse model and the level of IL-6, TNF- $\alpha$, and VEGF biomarkers in relevant tissues.

\section{MATERIALS AND METHODS}

\section{Experimental}

The Animal Experiments Local Ethics Committee first approved the protocol of Gaziantep University (N0o: 37 and Decision No: 2017/21), and the experimental studies started after signing an experimental animal request form and a written undertaking from Gaziantep University Experimental Animals Research Center. The study was conducted with 82 mice, two females, and 80 males. Mice 8-10 weeks old used in the study.

\section{Experimental Groups}

The study included both in vitro and in vivo experimental studies. In vivo, experimental study design consisted of 80 male mice assigned to four groups: a full-thickness skin defect (dorsal skin dissection with $12 \mathrm{~mm}$ diameter) was created in Group 1 (Control: C) (Biopsy punch sterile 12 mm 647 2022-01 Acuderm inc. USA), and these mice were injected with phosphate-buffered saline (PBS, EV solvent) and citrate buffer (streptozotocin (STZ) solvent) intraperitoneally (i.p). A full-thickness skin defect was created in Group 2 (Control + EV: C+EV), and these mice were injected with citrate buffer and EV (Mouse embryonic fibroblast EV) subcutaneously $(200 \mu \mathrm{g} / 200 \mu \mathrm{l})(\mathrm{Hu}$ et al. 2016). An experimental diabetic mouse model was created in Group 3 (Diabetic control: DC) with an i.p. STZ injection (150 mg/kg) (Deeds et al. 2011), a full-thickness skin defect was then created, and these mice were injected with PBS intraperitoneally. An experimental diabetic mouse model was formed in Group 4 (Diabetes + EV: D+EV). A full-thickness skin defect was created in this group and these mice received an EV subcutaneously injection.

The mice that were planned to undergo surgery were administered 80-100 mg/ kg ketamine (Ketalar, 002038, Eczacibaşi Sağlik Ürünleri Sanayi ve Ticaret AŞ., Lüleburgaz, Turkey) and 5-10 mg/kg xylazine (Alfazyne, 0804125-11, Alfasan, Woerden, Holland) intraperitoneally right before the surgical procedure.

Experimental diabetic mouse model and full-thickness skin defect model went through macroscopic imaging nearly every two days (on days $1,3,5,7,9,11,14,16,18$, and 21 after creating the full-thickness skin defect) to measure the wound area.

In our experimental study, mouse models of experimental diabetes and full-thickness skin defect were sacrificed on days 5, 7, 14, and 21. Since sacrification was performed on the same day as macroscopic imaging, macroscopic imaging was performed first, followed by sacrification and collection of tissue samples.

\section{Cell Culture}

The uteri of 2 mice that were on the 13th or 14th day of pregnancy were resected carefully by performing hysterectomy under sterile conditions, uterine horns were placed in Petri dishes, and each embryo was separated from the placenta and embryonic sac. Then the head and internal organs were severed. The tissue was cut using a sterile scalpel until it was finely chopped. The tissue was cut using a sterile scalpel until it was finely chopped. The chopped tissue was transferred to a $50 \mathrm{ml}$ falcon tube and digested using 10-12 ml 0.25\% trypsin-EDTA and the cells were carefully collected (Kurahara 2014).

It is possible to dilute cell types other than mouse embryonic fibroblasts under cell culturing conditions due to the highly proliferative nature 
of MEFs throughout the cell culture process. MEFs are also extremely adherent. Primary MEF cultures tend to be more stable than many other cell types, and they can be easily frozen to be used in the future. Cultures obtained as a result of several passages are generally accepted as a homogeneous population of mainly MEFs (Singhal et al. 2016). Mouse embryonic fibroblast cells were cultured in the culture medium by changing the culture medium every other day and following the cell culturing stages until they were confluent. MEF cells can be easily viewed under a microscope due to their fusiform shape. It was observed that the cells rapidly proliferated when they were cultured and entirely covered the base of the culture dish. Cell culturing was continued until MEF cells almost entirely covered the culture dish, since they were highly proliferative and adherent in the culture medium (Singhal et al. 2016).

\section{Cell Culture Conditions}

We used Dulbecco's Modified Eagle Medium (DMEM, Hyclone, SH30243.01 Utah/ABD) with 10\% FBS (Fetal Bovine Serum), 1\% penicillinstreptomycin for cell culture condition.

\section{Extracellular Vesicles Isolation Method Released from Mouse Embryonic Fibroblasts}

Total EV Isolation Solution (Thermo Fisher from cell culture, 4478359, USA) was used for the isolation of EV from MEFs found in cell culture media in flasks for EV Isolation from Mouse Embryonic Fibroblasts (Hu et al. 2016).

1- MEFs produced using primary cell culture method were proliferated with cell culture medium in flasks (T75, T150), following proliferation, MEFs and medium were detached from flasks with $0.25 \%$ trypsin-EDTA and removed into tubes.

2- MEFs and cell culture medium were centrifuged at $2000 \times \mathrm{g}(\mathrm{rcf})$ for 30 minutes.
3- After centrifugation, MEF cells were collected towards the bottom of the tubes, and the supernatant was transferred to a new tube.

4- $500 \mu \mathrm{l}$ was taken from the supernatant where MEF cells were released and half of 250 $\mu l$ total isolation solution was placed and mixed well.

5- The stirred supernatant was kept at $+4^{\circ}$ $C$ for about 1 night.

6- The supernatant was centrifuged at 10000 $\times g$ for 1 hour.

7- After the supernatant is discarded, the EV is invisible in the tube.

8- It was adjusted to put $50 \mu \mathrm{l}$ of PBS into a $1 \mathrm{ml}$ solution and mixed well and made ready.

\section{Experimental Diabetes Model}

$21 \mathrm{mg} / \mathrm{ml}$ of the prepared sodium citrate buffer was dissolved in STZ. Animals in which diabetes was going to be induced were intraperitoneally administered a single $150 \mathrm{mg} / \mathrm{kg}$ dose of STZ with an insulin injector (Deeds et al. 2011). Animals in the control and C+EV groups were intraperitoneally injected with sodium citrate buffer. Stz injection was made 48 hours before the groups were formed, and after diabetes measurement (blood and urine) was made, the procedures in the groups were passed.

\section{Extracellular Vesicles Administration}

Of the mice with full-thickness skin defects, EV was administered to the mice in Control EV and Diabetes EV groups. $200 \mu \mathrm{g}$ of EV was added to $200 \mu \mathrm{PBS}$ and injected subcutaneously at two different points around the wound ( $\mathrm{Hu}$ et al. 2016). Protein concentration measurement values of EVs were determined (Biotek Synergy $H 1, A B D)$ in Gaziantep University Medical Biochemistry Department laboratory. 


\section{Macroscopic Imaging and Measurement of the Wound Area}

Imaging of the grouped mice in which a fullthickness skin defect was created was conducted at a particular standard with fixed height, fixed illuminance, and using a right angle. Imaging was performed in mice with full-thickness skin defects on days $1,3,5,7,9,11,14,16,18$, and 21 to stage the progress of wound healing in all wounds, and area measurements were carried out using Adobe Photoshop 2018 cc software (Adobe Systems, New York, NY, http://www. adobe.com) based on pixels (Fang et al. 2016).

\section{Biochemical Assay}

Enzyme-linked immunosorbent assay (ELISA) was used to conduct in vitro quantitative measurements in serum, plasma, homogenates, and other biological fluids. All solutions in the assay kit were first brought to room temperature (Gan \& Patel 2013). Standard solutions were respectively loaded in the wells, and a standard graph was created by determining concentration based on the color using a microplate reader (Biotek Synergy H1, USA).

\section{Histopathological Evaluation}

Tissue samples sized approximately $3 \times 2 \mathrm{~cm}$ obtained from all mice sacrificed at the end of postoperative days 5, 7, 14, and 21 were fixed in $10 \%$ neutral formalin solution and then embedded in parafin blocks. Slices of nearly 5 $\mu \mathrm{m}$ thickness obtained from the paraffin blocks were stained using the Hematoxylin-Eosin (HE) and Masson's Trichrome (MT) methods and evaluated under a light microscope (Luna 1968). Histopathological evaluation was performed according to the wound healing assessment score (Sagliyan et al. 2010).

\section{Statistical Analysis}

Statistical analysis was performed using the Statistical Package for Social Science (SPSS) version 24.0 (SPSS inc., Chicago, USA). Differences between the mean values in more than two independent groups were evaluated using One-Way ANOVA since the measurements satisfied the parametric test assumptions ( $p>0.05)$. Differences between the groups were determined using post-hoc LSD. The results were evaluated using $p$ values at $95 \%$ confidence level, and $p<0.05$ was considered statistically significant.

\section{RESULTS}

\section{Macroscopic Comparison of the Wound Areas Between The Groups}

According to the figure 2 comparing the wound area according to days in mice in the C, C+EV, $D C$, and D+EV groups in which a full-thickness skin defect was created, there was no significant difference on day 1 , when the said skin defect was created $(p>0.05)$. On the other hand, there was a statistically significant difference between macroscopic imaging days 3, 5, 7, 9, 11, 14, 16, 18, and 21 (Figure 2) $(p<0.05)$. On these days, there was a statistically significant difference between the DC group and all the other groups (,$C+E V$, $D+E V)(p<0.05)$. The wound area of the DC group was found to be larger than other groups. On macroscopic imaging days 5, 7, and 9, there was a statistically significant difference between the $C$ and $\mathrm{C}+$ EV groups $(p<0.05)$. On these days, wound areas of $\mathrm{C}+\mathrm{EV}$ group were found to shrink more than $C$ group. On macroscopic imaging days 7 , 9 , and 11 , there was a statistically significant difference between the D+EV and C+EV groups $(p<0.05)$. The wound areas of the $C+E V$ group shrunk more than the D + EV group. 
Photos of the subjects in these groups in which a wound model was created were provided (Figure 1). Photos of the wound areas in one mouse randomly selected from each group (C, C+EV, DC, D+EV) in which a full-thickness skin defect was created and macroscopic imaging was performed until day 21 were provided (Figure 1). According to the examination on day 21, almost all mice in all groups exhibited hair growth, and the wound areas and scars were smaller in the C+EV group than in the other groups after the back hair of the mice was shaved. It was observed that the wound area was not considerably smaller, and the scar was more distinct in the DC group compared to the other groups.

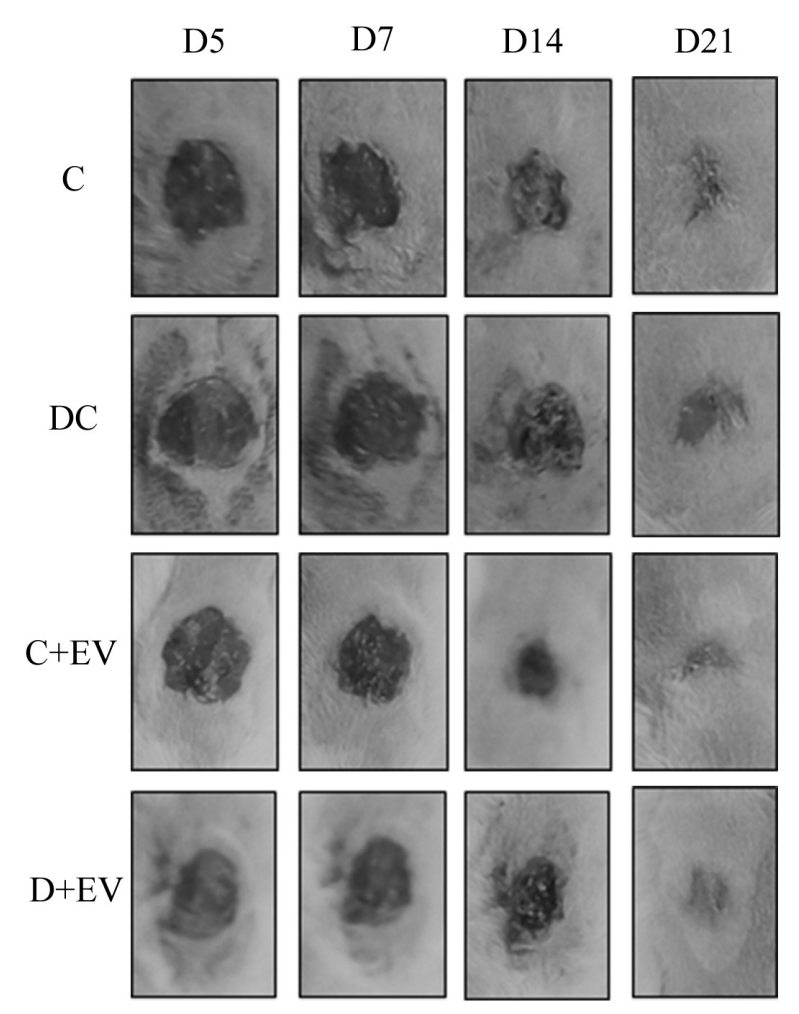

Figure 1. Comparative photos of one animal were randomly selected from each group on days 5,7 , 14, and 21. C: Control group, DC: Diabetic Control Group, C+EV: Control group that was administered Extracellular Vesicles, D+EV: Diabetic control group that was administered Extracellular Vesicles. D: Day.

\section{Biochemical Assay}

In this study, the biochemical parameters VEGF, TNF- $\alpha$, and IL- 6 were assayed. The amount of these proteins in tissue samples was determined on postoperative days $5,7,14$, and 21 in pg/mg, and standard deviations were provided based on statistical analyses (Figures $3 a-b-c)$. The amount of VEGF protein in tissue samples of the groups exhibited a statistically significant difference only on day $5(p<0.05)$. The amount of this protein was average $200 \mathrm{pg} / \mathrm{mg}$ level in the C+EV group on day 14, after which it started to drop in all groups. The amount of TNF- $\alpha$ was similar in all groups, especially on day 21 (Figure $3 a-b)$. There was no statistically significant difference between the groups in terms of the amount of the $I L-6$ protein $(p>0.05)$. The $I L-6$ level continued to drop until day 14 , after which it started to increase in all groups (Figure 3c).

\section{Histopathological Evaluation}

There was no statistically significant difference between the groups in terms of wound healing parameters at the end of day 5 (Table I). However, the control group had the most distinct granulation tissue, D + EV group had the lowest, and the C+EV group had the highest amount of angiogenesis (Figures 4-5). There was a statistically significant difference between the groups in terms of granulation tissue, inflammatory cell, and angiogenesis scores on day 7 (Table I). Evaluation of the groups in terms of the number of inflammatory cells showed that the D + EV group had milder inflammatory changes compared to the other three groups. Similar to the granulation tissue, $\mathrm{C}$ and $\mathrm{C}+\mathrm{EV}$ groups had more distinct angiogenesis than the DC and D + EV groups (Figure 5). There was no statistically significant difference between the groups in terms of wound healing parameters at the end of day 14 (Table I). Angiogenesis became more distinct in all groups on day 14 (Figure 6). 


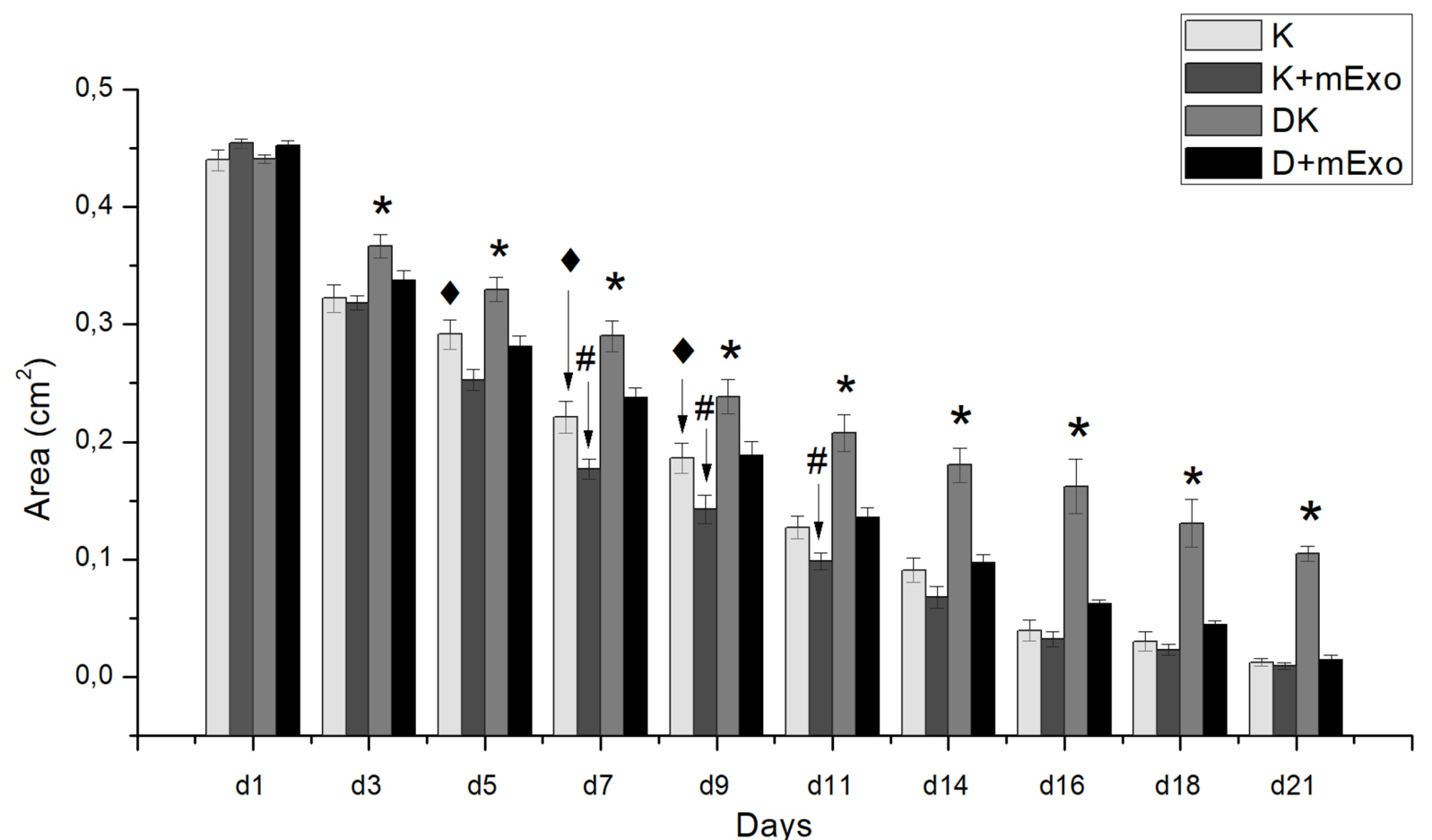

Figure 2. Graph comparing the mean wound areas in the respectively Control, Control Extracellular Vesicles, Diabetic Control, and Diabetes Extracellular Vesicles Groups according to days. C: Control, C+EV: Control Extracellular Vesicles, DC: Diabetic Control, D+EV: Diabetes Extracellular Vesicles. $p<0.05$ indicates that the difference between the groups in terms of mean values is statistically significant. *: Indicates that there is a statistically significant difference between the DC group and all the other groups (C, C+EV, D+EV). \#: Indicates that there is a statistically significant difference between the C+EV and D+EV groups. $\$$ : Indicates that there is a statistically significant difference between the $\mathrm{C}$ and $\mathrm{C}+\mathrm{EV}$ groups. The error bars shown in the graph indicate the standard error. Represents $\mathbf{n}=\mathbf{2 0}$ for each group.

There was a statistically significant difference, considering the wound healing parameters, between the groups only in terms of angiogenesis on day 21 (Table I). Angiogenesis was more distinct in the DC group than the other groups on day 21, and it became more distinct in other groups on day 14 (Figure 6-7).

\section{CONCLUSIONS}

In light of this information, it is thought that EV isolated from mouse embryonic fibroblasts can contribute to the decrease in wound areas during the wound healing process. EV increased the impact of VEGF, and therefore promoted angiogenesis, wherein angiogenesis increased the transport of cells and the necessary oxygen and nutrients to the wound area. The fact that EV did not affect the IL- 6 and TNF- $\alpha$ cytokines can be considered as a drawback for the wound healing process. However, inflammation continuing for a particular time can be beneficial in terms of tissue oxygenation and wound healing in diabetic wounds.

\section{DISCUSSION}

This study aimed to investigate the effect of EV isolated from mouse embryonic fibroblasts on wound healing in an experimental diabetic mouse model and mice with a full-thickness skin defect. This experimental study is one of the first studies conducted with biochemical and histopathological findings by carrying 


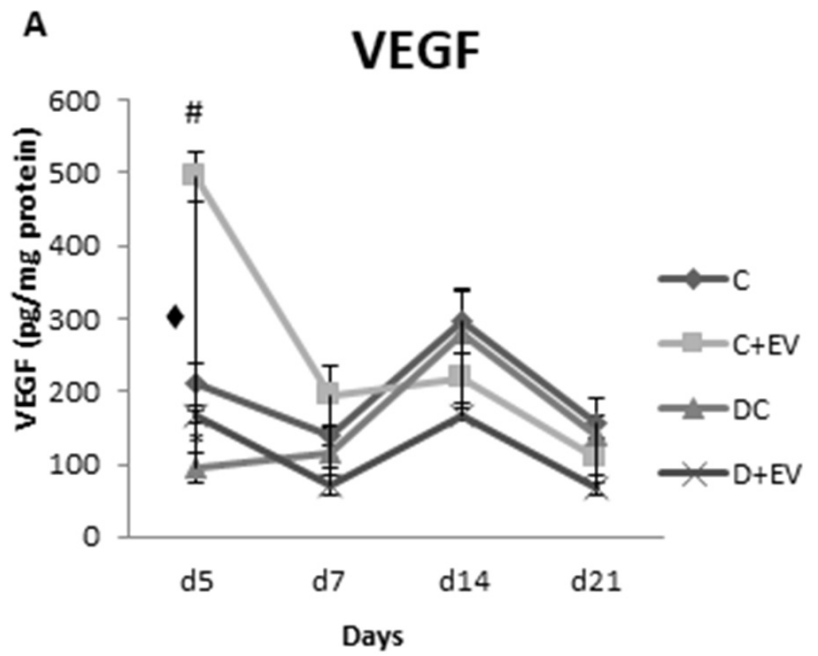

B

TNF- $\alpha$
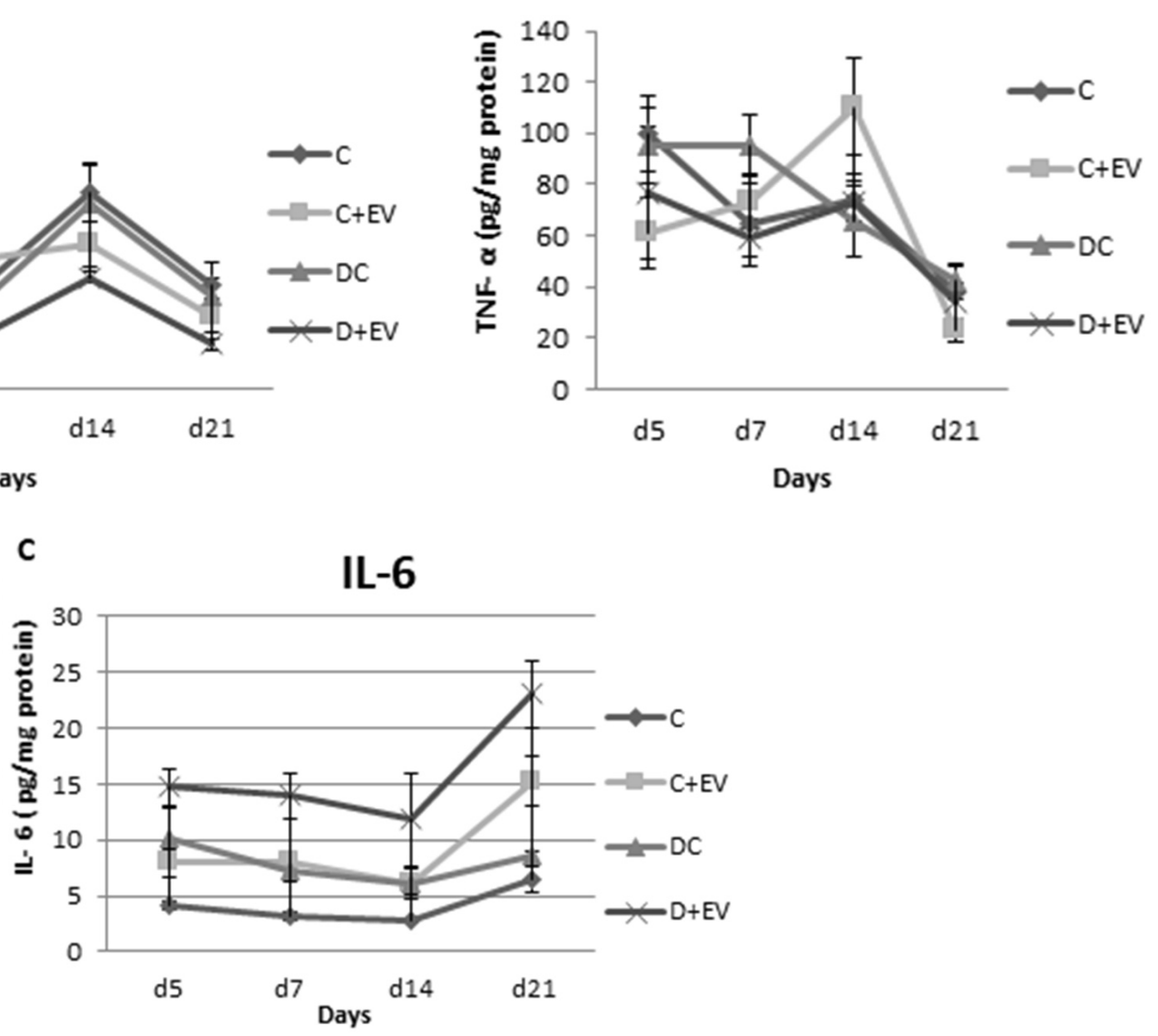

Figure 3. a. Distribution of VEGF levels by groups and days. \#: Indicates that there is a statistically significant difference between the $\mathrm{C}+\mathrm{EV}$ and $\mathrm{D}+\mathrm{EV}$ groups. *: Indicates that there is a statistically significant difference between the DC group and all the other groups (C, C+EV, D+EV). $\downarrow$ : Indicates that there is a statistically significant difference between the $\mathrm{C}$ and $\mathrm{C}+\mathrm{EV}$ groups. $\mathbf{b}$. Distribution of TNF- $\alpha$ levels by groups and days.c. Distribution of IL- 6 levels by groups and days.

out macroscopic area measurements in order to determine the effects of EV isolated using a primary embryonic fibroblast cell culture on wound healing in diabetic mice provided with a wound. Han et al. (2015) conducted a study based on the information that MMP-14 promotes angiogenesis and administered MMP14-containing EV extracted from the fibroblasts in human cornea to the human umbilical vein endothelial cells (HUVEC) and calf pulmonary artery endothelial cells (CPAEC). Consequently, it was reported that angiogenesis was accelerated in these cells, and this could have an effect on wound healing (Casado-Díaz et al. 2020, Han et al. 2015). In this experimental study, macroscopic imaging showed that the wound areas became smaller, which was consistent with the results obtained by Han et al. (2015). In these studies, wound areas were found to be smaller in groups that were administered $\mathrm{EV}$, which was attributed to the interaction between VEGF that are thought to be present in EV. It was reported that the said interaction increased angiogenesis, leading to higher nutrient and $\mathrm{O}^{2}$ transport to the tissues and in turn to smaller wound areas. 
Table I. Histopathological findings on days 5, 7, 14, and 21 of wound healing.

\begin{tabular}{|c|c|c|c|c|}
\hline \multicolumn{5}{|c|}{ GROUPS } \\
\hline & \multicolumn{4}{|c|}{ 5. Day } \\
\hline & $\begin{array}{c}C \\
(n=20)\end{array}$ & $\begin{array}{c}C+E V \\
(n=20)\end{array}$ & $\begin{array}{c}D+E V \\
(n=20)\end{array}$ & $\begin{array}{c}D C \\
(n=20)\end{array}$ \\
\hline Re-epithelialization & $0.83 \pm 0.17$ & $0.67 \pm 0.21$ & $0.67 \pm 0.21$ & $0.83 \pm 0.17$ \\
\hline Granulation texture & $0.67 \pm 0.21$ & $0.33 \pm 0.21$ & $0.50 \pm 0.22$ & $0.50 \pm 0.22$ \\
\hline Collagen deposition & $0.00 \pm 0.00$ & $0.00 \pm 0.00$ & $0.00 \pm 0.00$ & $0.00 \pm 0.00$ \\
\hline Inflammatory cell & $3.00 \pm 0.00$ & $3.00 \pm 0.00$ & $3.00 \pm 0.00$ & $3.00 \pm 0.00$ \\
\hline Angiogenesis & $1.33 \pm 0.21$ & $1.67 \pm 0.21$ & $1.00 \pm 0.00$ & $1.33 \pm 0.21$ \\
\hline \multirow[t]{3}{*}{ Ulcer } & $0.00 \pm 0.00$ & $0.00 \pm 0.00$ & $0.00 \pm 0.00$ & $0.00 \pm 0.00$ \\
\hline & \multicolumn{4}{|c|}{ 7. Day } \\
\hline & $\begin{array}{c}C \\
(n=20)\end{array}$ & $\begin{array}{c}C+E \boldsymbol{V} \\
(n=20)\end{array}$ & $\begin{array}{c}\text { D+EV } \\
(n=20)\end{array}$ & $\begin{array}{c}D C \\
(n=20)\end{array}$ \\
\hline Re-epithelialization & $1.00 \pm 0.00$ & $1.00 \pm 0.00$ & $1.00 \pm 0.00$ & $1.00 \pm 0.00$ \\
\hline Granulation texture & $1.83 \pm 0.17^{a b}$ & $2.00 \pm 0.00^{a}$ & $1.33 \pm 0.21^{b}$ & $1.33 \pm 0.21^{b}$ \\
\hline Collagen deposition & $0.83 \pm 0.17$ & $1.00 \pm 0.00$ & $1.00 \pm 0.00$ & $1.00 \pm 0.00$ \\
\hline Inflammatory cell & $3.00 \pm 0.00^{a}$ & $3.00 \pm 0.00^{a}$ & $2.17 \pm 0.17^{b}$ & $3.00 \pm 0.00^{a}$ \\
\hline Angiogenesis & $2.83 \pm 0.17^{a}$ & $2.67 \pm 0.21^{a b}$ & $2.17 \pm 0.17^{b c}$ & $1.33 \pm 0.21^{c}$ \\
\hline \multirow[t]{3}{*}{ Ulcer } & $0.00 \pm 0.00$ & $0.33 \pm 0.21$ & $0.50 \pm 0.22$ & $0.00 \pm 0.00$ \\
\hline & \multicolumn{4}{|c|}{ 14. Day } \\
\hline & $\begin{array}{c}\text { C } \\
(n=20)\end{array}$ & $\begin{array}{c}\boldsymbol{C}+\boldsymbol{E} \boldsymbol{V} \\
(\mathrm{n}=20)\end{array}$ & $\begin{array}{c}\boldsymbol{D}+\boldsymbol{E} \boldsymbol{V} \\
(\mathrm{n}=20)\end{array}$ & $\begin{array}{c}D C \\
(n=20)\end{array}$ \\
\hline Re-epithelialization & $1.33 \pm 0.21$ & $1.33 \pm 0.21$ & $1.33 \pm 0.21$ & $1.83 \pm 0.40$ \\
\hline Granulation texture & $2.33 \pm 0.21$ & $2.67 \pm 0.21$ & $2.17 \pm 0.17$ & $2.50 \pm 0.22$ \\
\hline Collagen deposition & $1.83 \pm 0.31$ & $2.00 \pm 0.26$ & $1.50 \pm 0.22$ & $2.33 \pm 0.21$ \\
\hline Inflammatory cell & $2.17 \pm 0.31$ & $1.50 \pm 0.22$ & $1.83 \pm 0.17$ & $1.50 \pm 0.22$ \\
\hline Angiogenesis & $2.50 \pm 0.22$ & $2.33 \pm 0.33$ & $2.33 \pm 0.33$ & $2.33 \pm 0.33$ \\
\hline \multirow[t]{3}{*}{ Ulcer } & $1.67 \pm 0.42$ & $2.00 \pm 0.37$ & $1.67 \pm 0.33$ & $2.00 \pm 0.45$ \\
\hline & \multicolumn{4}{|c|}{ 21. Day } \\
\hline & $\begin{array}{c}C \\
(n=20)\end{array}$ & $\begin{array}{c}\text { C+EV } \\
(n=20)\end{array}$ & $\begin{array}{c}\text { D+EV } \\
(n=20)\end{array}$ & $\begin{array}{c}D C \\
(n=20)\end{array}$ \\
\hline Re-epithelialization & $2.17 \pm 0.31$ & $2.50 \pm 0.22$ & $2.83 \pm 0.17$ & $2.66 \pm 0.21$ \\
\hline Granulation texture & $2.83 \pm 0.17$ & $3.00 \pm 0.00$ & $3.00 \pm 0.00$ & $3.00 \pm 0.00$ \\
\hline Collagen deposition & $2.83 \pm 0.17$ & $2.50 \pm 0.22$ & $2.83 \pm 0.17$ & $3.00 \pm 0.00$ \\
\hline Inflammatory cell & $1.33 \pm 0.33$ & $0.83 \pm 0.17$ & $1.00 \pm 0.00$ & $1.00 \pm 0.00$ \\
\hline Angiogenesis & $1.83 \pm 0.31^{b}$ & $1.50 \pm 0.22^{b}$ & $1.83 \pm 0.31^{b}$ & $3.00 \pm 0.00^{a}$ \\
\hline Ulcer & $2.67 \pm 0.21$ & $3.00 \pm 0.00$ & $3.00 \pm 0.00$ & $3.00 \pm 0.00$ \\
\hline
\end{tabular}

*Each value $(a, b, c)$ is expressed by its mean \pm standart deviation. Those values within a row followed by the same letter do not differ significantly $(p \leq 0.05)$.

In this study, the wound healing process was faster, wound closure took place sooner, and the scars disappeared in the groups that were administered EV compared to the other groups. Wound healing progressed more rapidly in mice of the same age group. In a study of Bao et al. (2009), a diabetic mouse model was created to compare VEGF levels according to the days of wound healing, and it was found that VEGF was at the lowest level on day 5 in 


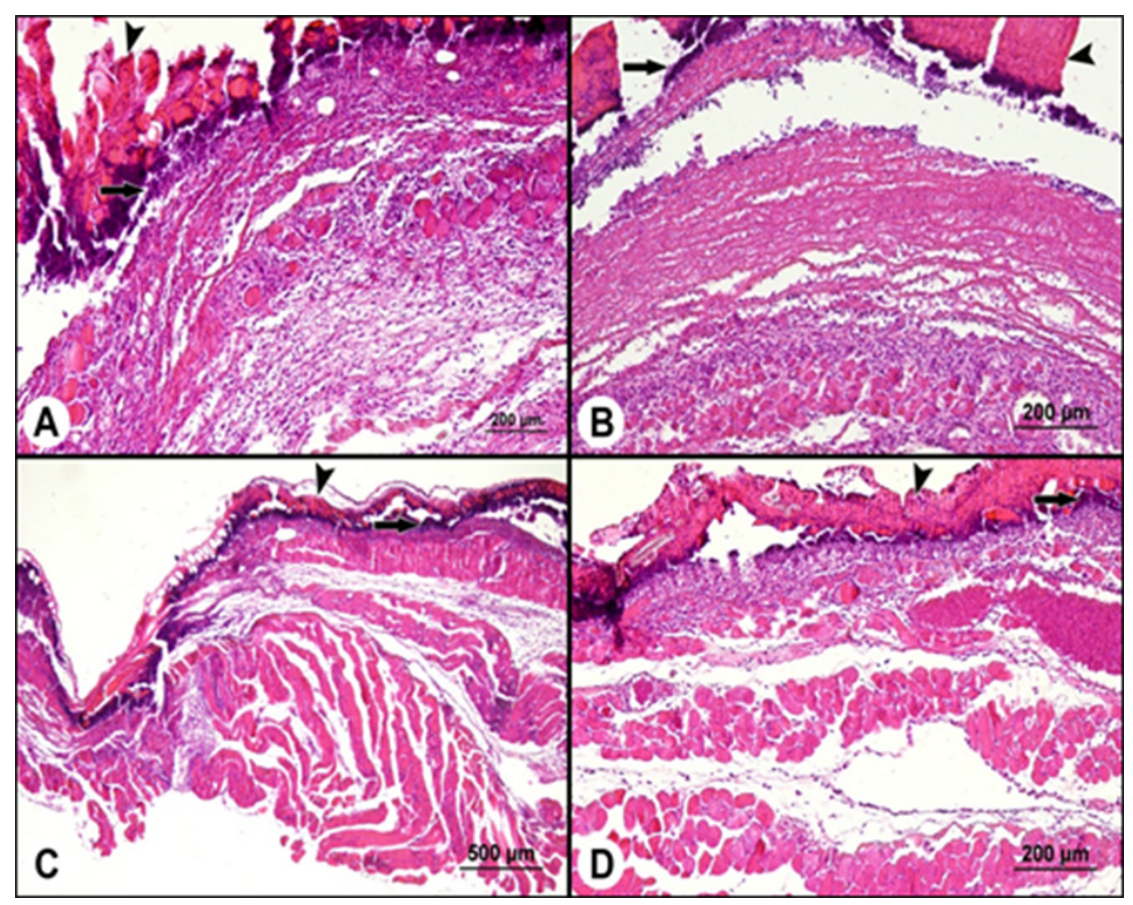

Figure 4. On day 5, the appearance of wound healing was shown by scabs (arrowheads) and inflammatory cell infiltrations (arrows). a. Group C; b. Group C+EV; c. Group DC; d. Group $D+E V$, HE staining.

diabetic mice (Bao et al. 2009). In another study by Jacobi et al. (2002) investigating the effects of VEGF on wound healing, it was observed that the receptors of VEGF could inhibit its angiogenic effect. According to the hypothesis of Jacobi et al. (2002), VEGF transfer had a negative effect on wound healing in diabetic mice. They reported that while VEGF function was necessary for wound angiogenesis, it was not required for wound closure (Jacobi et al. 2002).

The amount of VEGF protein in tissue samples of the groups exhibited a statistically significant difference only on day $5(p<0.05)$. There was a statistically significant difference between the DC group and the $C$ and $C+E V$ groups, between the D+EV and C+EV groups, and the $C$ and $C+E V$ groups. VEGF level was high in the Control and D+EV groups and lowest in the DC group on day 5 . This study showed that mainly the VEGF protein was at the highest level on day 5 in comparison to other studies. There was no statistically significant difference on the other days, after which the amount of VEGF protein started to drop. Histopathological evaluation showed that VEGF was present in higher levels in the angiogenesis and granulation tissue of the $\mathrm{C}$ and $\mathrm{C}+\mathrm{EV}$ groups than the other groups on day 7 (Table I) (Figure 3c). The histopathological evaluation also showed that angiogenesis was considerably more distinct in the DC group than the other groups on day 21 (Table I) (Figure 5). The distinct angiogenesis in the DC group on these days was considered to be due to the delay in angiogenesis. Accordingly, the increased VEGF level observed in this study was consistent with the findings of Bao et al. (2009), Jacobi et al. (2002). Frank et al. (1995) reported that increased VEGF levels accelerated the wound healing process and promoted angiogenesis. They also stated that the most important causes of increased VEGF levels were GF and keratinocytes (Bao et al. 2009, Frank et al. 1995, Jacobi et al. 2002). According to Bao et al. (2009), especially the amount of VEGF dropped down to the lowest level, and angiogenesis was decreased on day 5 in diabetic mice. In this study, VEGF was at the lowest level in the DC group on day 5, but the amount of VEGF was higher in the D+EV 


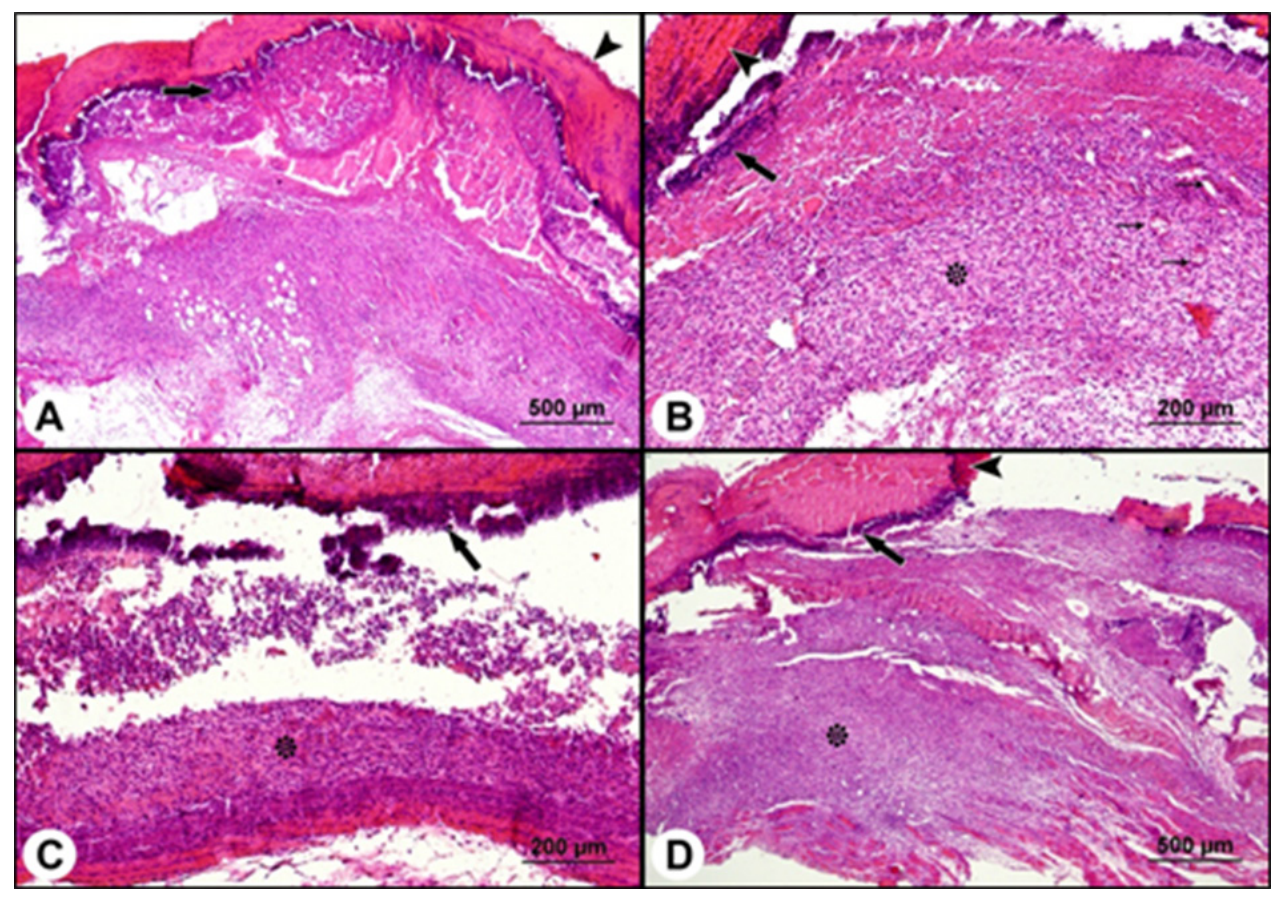

Figure 5. On the $7^{\text {th }}$ day, scab (arrowheads), dead neutrophil cell infiltrations under the shell (arrows), and appearance of early granulation tissue (asterisks). a. Group C; b. Group C+EV; c. Group DC; d. Group D+EV, HE staining.

group (Bao et al. 2009). Although there was no statistically significant difference on the other days, the VEGF level was higher in the C and DC groups than in the $\mathrm{C}+\mathrm{EV}$ and $\mathrm{D}+\mathrm{EV}$ groups. It was found that EV increased the amount of VEGF in scar tissue and increased VEGF level accelerated the wound healing process by promoting angiogenesis. Saaristo et al. (2006) reported that growth factors and cytokines increased the amount of VEGF in would healing. Angiogenesis is necessary for the delivery of cells as well as the necessary $\mathrm{O}_{2}$ and nutrients to tissues. Increased VEGF and GF levels were observed to promote angiogenesis in tissues (Saaristo et al. 2006). The positive effects of increased VEGF on angiogenesis were also observed in our results. Our histopathological findings also indicate that the number of inflammatory cells in the wound area was increased with increased angiogenesis. Based on this information, it was thought that the increased level of VEGF in this study stemmed from EV isolated from mouse embryonic fibroblasts.
There was no statistically significant difference between the groups in terms of the amount of the IL-6 protein in tissues $(p>0.05)$. In their study, Their findings concerning the IL-6 protein levels in the first days of wound healing were similar to the results of this study, whereas the findings on the other days were different from those in our study. Their findings concerning TNF- $\alpha$ protein levels were consistent with the results of this study. Khanna et al. (2s010) investigated the effects of macrophage dysfunction on the amelioration of inflammation in the wounds of diabetic mice and evaluated the IL- 6 and TNF- $\alpha$ protein levels in scar tissue. They found statistically significant IL- 6 and TNF- $\alpha$ protein levels. Notably, there was a difference in TNF- $\alpha$ protein levels on all days, except for the first day (Khanna et al. 2010). Unlike this study, we did not identify a statistically significant difference in IL- 6 and TNF- $\alpha$ protein levels in tissues measured throughout the wound healing process, and therefore, our results were not consistent with the said study. 

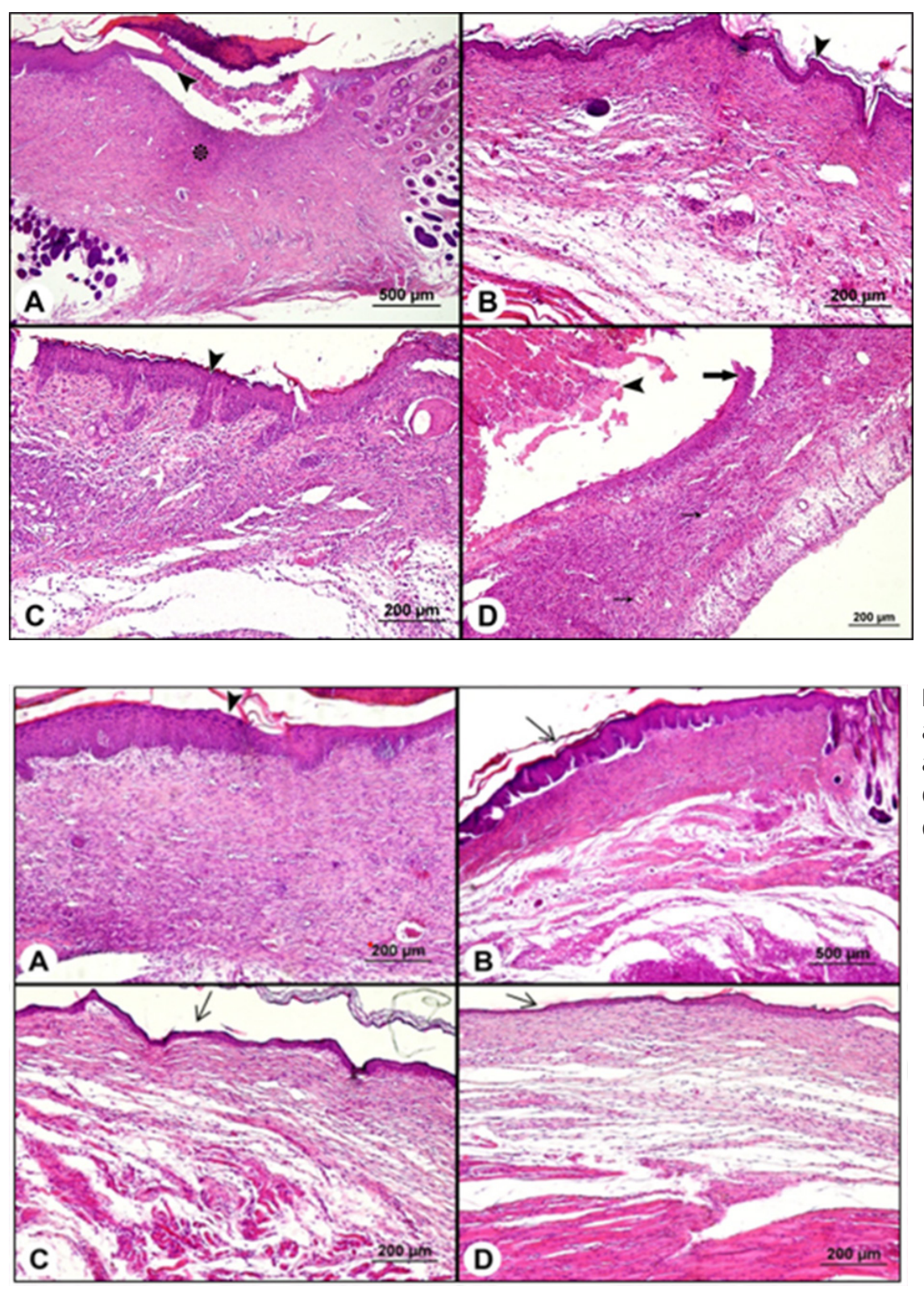

Figure 6. The 14th-day appearance of the wound area. a. Group C, sub-crust partial reepithelization (arrowhead) and appearance of granulation tissue (asterisk); b. C+EV group, appearance of completed epithelialization (arrowhead); c. DC group, complete, but appearance of immature epithelization (arrowhead); d. D + EV group, scab (arrowhead) and partial reepithelization (arrow) HE staining.
Figure 7. The $14^{\text {th }}$-day appearance of the wound area. a. Group C; b. Group C+EV; c. Group DC; d. Group D+EV, HE staining.

\section{Acknowledgments}

We gratefully thank the Research Project Management Unit University of Gaziantep (Grant: TF. DT.18.13) for funding this study. No potential conflict of interest relevant to this article was reported. Research Project Management Unit University of Gaziantep.

\section{REFERENCES}

BAO P, KODRA A, TOMIC-CANIC M, GOLINKO MS, EHRLICH HP \& BREM H. 2009. The role of vascular endothelial growth factor in wound healing. JSR 153(2): 347-358.
BARRIENTOS S, STOJADINOVIC O, GOLINKO MS, BREM H \& TOMICCANIC M. 2008. Growth factors and cytokines in wound healing. Wound Rep Reg 16(5): 585-601.

CASADO-DÍAZ A, QUESADA-GÓMEZ JM \& DORADO G. 2020. Extracellular vesicles derived from mesenchymal stem cells (msc) in regenerative medicine: Applications in skin wound healing. Front Bioeng Biotechnol 8: 146.

DEEDS M, ANDERSON J, ARMSTRONG A, GASTINEAU D, HIDDINGA H, JAHANGIR A, EBERHARDT N \& KUDVA Y. 2011. Single dose streptozotocin-induced diabetes: Considerations for study design in islet transplantation models. LAL 45(3): $131-140$. 
FANG S, XU C, ZHANG Y, XUE C, YANG C, BI H, QIAN X, WU M, JI K \& ZHAO Y. 2016. Umbilical cord-derived mesenchymal stem cell-derived exosomal micrornas suppress myofibroblast differentiation by inhibiting the transforming growth factor- $\beta /$ smad2 pathway during wound healing. STEM CELLS Transl Med 5(10): 1425-1439.

FRANK S, HÜBNER G, BREIER G, LONGAKER MT, GREENHALGH DG \& WERNER S. 1995. Regulation of vascular endothelial growth factor expression in cultured keratinocytes. Implications for normal and impaired wound healing. JBC 270(21): 12607-12613.

GAN SD \& PATEL KR. 2013. Enzyme immunoassay and enzyme-linked immunosorbent assay. J Invest Dermatol 133(9): e12.

HAN K-Y, DUGAS-FORD J, SEIKI M, CHANG J-H \& AZAR DT. 2015. Evidence for the involvement of mmp14 in $\mathrm{mmp2}$ processing and recruitment in exosomes of corneal fibroblasts. IOVS 56(9): 5323-5329.

HAUB O \& GOLDFARB M. 1991. Expression of the fibroblast growth factor-5 gene in the mouse embryo. Development, 112(2), 397-406.

HORMOZI M, ASSAEI R \& BOROUJENI MB. 2017. The effect of aloe vera on the expression of wound healing factors (tgfß1 and bfgf) in mouse embryonic fibroblast cell: In vitro study. Biopha 88: 610-616.

HU L, WANG J, ZHOU X, XIONG Z, ZHAO J, YU R, HUANG F, ZHANG H \& CHEN L. 2016. Exosomes derived from human adipose mensenchymal stem cells accelerates cutaneous wound healing via optimizing the characteristics of fibroblasts. Sci Rep 6: 32993.

JACOBI J, JANG JJ, SUNDRAM U, DAYOUB H, FAJARDO LF \& COOKE JP. 2002. Nicotine accelerates angiogenesis and wound healing in genetically diabetic mice. AJP 161(1): 97-104.

KHANNA S, BISWAS S, SHANG Y, COLLARD E, AZAD A, KAUH C, BHASKER V, GORDILLO GM, SEN CK \& ROY S. 2010. Macrophage dysfunction impairs resolution of inflammation in the wounds of diabetic mice. Plos One 5(3): e9539.

KURAHARA C. 2014. Manipulating the mouse embryo under protocols for culture of jm8 es cells, $4^{\text {th }}$ ed., California: CSHL Press.

LUNA L. 1968. Manual of histologic staining methods. Institute of pathology, armed forces. NY, USA: McGraw-Hill.

QIN Y, SHIN JH, YOON J-H \& PARK S-H. 2018. Embryonic fibroblasts promote antitumor cytotoxic effects of $\mathrm{cd} 8+\mathrm{t}$ cells. Front Immunol 9: 685.

RODERO MP \& KHOSROTEHRANI K. 2010. Skin wound healing modulation by macrophages. IJCEP 3(7): 643.

SAARISTO A, TAMMELA T, FĀRKKILĀ A, KÄRKKÄINEN M, SUOMINEN E, YLA-HERTTUALA S \& ALITALO K. 2006. Vascular endothelial growth factor-c accelerates diabetic wound healing. AJP 169(3): 1080-1087.
SAGLIYAN A, CERIBASI A, GUNAY C, HAN M, BENZER F \& KANDEMIR M. 2010. Effects of dietary supplementation with whey proteins on surgical wound healing in rats. Rev Med Vet 161: 455-462.

SINGHAL PK, SASSI S, LAN L, AU P, HALVORSEN SC, FUKUMURA D, JAIN RK \& SEED B. 2016. Mouse embryonic fibroblasts exhibit extensive developmental and phenotypic diversity. Paper presented at the Proceedings of the National Academy of Sciences.

\section{How to cite}

BOZKURT AS, KAPLAN DS, ÇERIBAŞI AO, ORKMEZ M, ÇANAK A \& TARAKÇIOĞLU M. 2021. An Investigation of The Effect of Extracellular Vesicles Isolated from Mouse Embryonic Fibroblasts on Wound Healing in an Experimental Diabetic Mouse Model. An Acad Bras Cienc 94: e20201562. DOI 10.1590/0001-3765202120201562.

Manuscript received on October 5, 2020;

accepted for publication on January 7, 2021

\section{AHMET S. BOZKURT ${ }^{1}$}

http://orcid.org/0000-0002-7293-0974

\section{DAVUT S. KAPLAN ${ }^{1}$}

http://orcid.org/0000-0003-4663-209X

\section{ALI O. ÇERIBASSI ${ }^{2}$}

http://orcid.org/0000-0002-6096-4042

\section{MUSTAFA ORKMEZ ${ }^{3}$}

http://orcid.org/0000-0001-5255-0504

\section{ASUMAN ÇANAK}

http://orcid.org/0000-0003-2428-0978

\section{MEHMETTARAKÇIOĞLU}

http://orcid.org/0000-0002-2398-8264

${ }^{1}$ University of Gaziantep, Department of Physiology, Medical Faculty, Health Sciences Institution, 27310, Gaziantep, Turkey

${ }^{2}$ University of Firat, De partment of Pathology, Faculty of Veterinary, 23119, Elazı̆̆, Turkey

${ }^{3}$ University of Gaziantep, Department of Medical Biochemistry, Medical Faculty, Health Sciences Institution, 27310, Gaziantep, Turkey

Correspondence to: Ahmet Sarper Bozkurt E-mail:asbozkurt@gantep.edu.tr

\section{(cc) BY}

